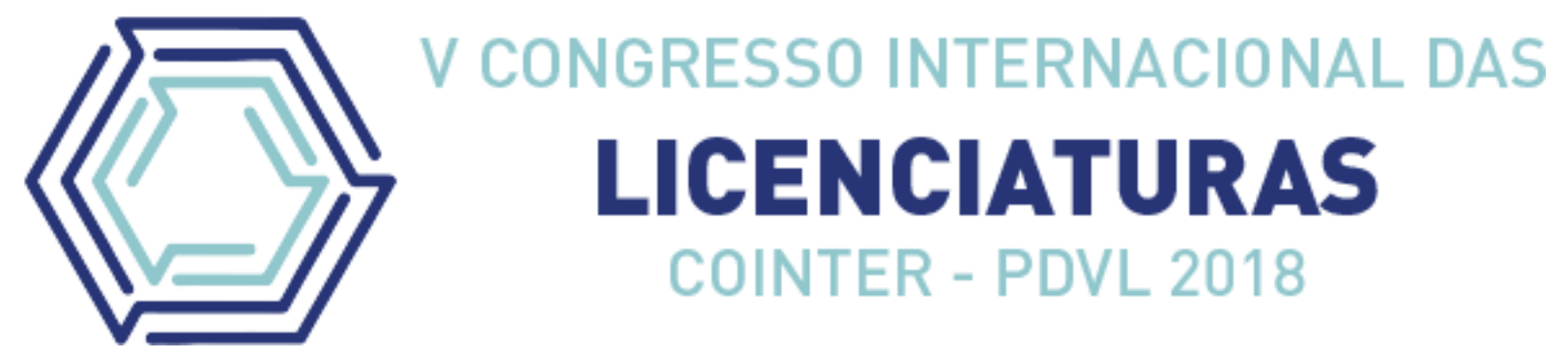

\title{
AS RELAÇÕES ÉTNICO-RACIAIS NAS VIVÊNCIAS DO ENSINO E DA APRENDIZAGEM ESCOLAR
}

\section{THE RELATIONS ETHNIC AND RACIAL ON THE SCHOOL TEACHING AND LEARNING COEXISTENCE} Apresentação: Pôster

Vitor Gabriel Moura Firmino da Silva ${ }^{1}$; João Rafael da Silva Carvalho²; Vidal Gabriel da Silva Carvalho ${ }^{3}$; Rafael Manoel de Souza Silva ${ }^{4}$ : Mádson Francisco da Silva ${ }^{5}$

\section{DOI: https://doi.org/10.31692/2358-9728.VCOINTERPDVL.2018.00184}

\section{Introdução}

O presente texto discorre acerca das relações étnico-raciais e sua contribuição no processo de ensino e aprendizagem. Desse modo, ressalta a importância da democratização da educação, ou seja, de uma maior qualidade do ensino, sem conteúdos tendenciosamente hierarquizados a fim de compreender a efetivação das relações na sociedade e suas reproduções nas vivências escolares.

Desta forma, a grande problemática consiste no processo de ensino para o fomento da aprendizagem. Pois, na maioria das vezes, não há problematização desse tema entre os professores e os alunos, por não enxergarem nessa temática um objeto de estudo necessário. A falta de debate, bem como as intolerâncias frente a diversidade vigente, trouxeram a necessidade de se fazer estudos sobre os motivos que levam ao epicentro dos conflitos, até às causas de suas reproduções.

\section{Fundamentação Teórica}

É, precipuamente, necessário ter-se conhecimento da plurietnicidade e multirracialidade brasileira. Nessa perspectiva, evoca-se o processo de formação cultural e identitária do país. A identidade brasileira fora, tão somente, formada a partir de um caldeirão

\footnotetext{
${ }^{1}$ Licenciatura em Geografia, Universidade de Pernambuco-UPE, vitgbriel@gmail.com

${ }^{2}$ Licenciatura em Geografia, Universidade de Pernambuco, joaorafael1557@gmail.com

3 Licenciatura em Geografia, Universidade de Pernambuco, vidallcarvalho@gmail.com

${ }^{4}$ Graduando em Geografia, Universidade de Pernambuco-UPE, rafaelmanoel2011@hotmail.com

${ }^{5}$ Mestre em Educação, Universidade de Pernambuco, mamadson123@hotmail.com
} 
cultural que uniu matrizes de vários grupos étnico-raciais e que acabaram tornando-o autêntico, sobretudo, por sua miscigenação.

Isto posto, corrobora Petruccelli (2013) afirmando que "o país se se expressava numa preocupação sistêmica com a origem multirracial do povo brasileiro, percebida como fonte de contradições sociais e obstáculo à construção de uma identidade nacional". À vista disso, é notório a reprodução dos resultados dos conflitos entre os grupos étnico-raciais (os historicamente dominantes em detrimento dos dominados). Na educação, essa reprodução gera uma hierarquização entre o conhecimento, exemplificada pelo clássico "eurocentrismo" ou "americanismo" apresentado pelos livros didáticos.

Destarte, a educação étnico-racial é necessária, pois age na cidadania possibilitando sua aplicabilidade de forma crítica e consciente, mostrando a importância da tolerância, sobretudo no Brasil, já que somos frutos de matrizes díspares. Para ratificar esse pensamento tem-se a Lei 10.639/03 e o Parecer CNE/CP 003/04 que enceta no âmbito educacional o termo "educação das relações étnico-raciais": "[...] A educação das relações étnico-raciais impõe aprendizagens entre brancos e negros, trocas de conhecimentos, quebra de desconfianças, projeto conjunto para construção de uma sociedade, justa, igual, equânime"(BRASIL, 2004, p. 6).

Para tanto, urge-se de práticas pedagógicas que abordem as matrizes e suas influências à nossa identidade, especialmente, no exercício da cidadania. Logo, é necessário que a gênese deste processo se dê nas séries iniciais da formação escolar fundamental ao indivíduo, pois segundo a Lei de Diretrizes e Bases da Educação Nacional (Lei 9394/96) Art. 29. “A educação infantil, primeira etapa da educação básica, tem como finalidade o desenvolvimento integral da criança de até 5 (cinco) anos, em seus aspectos físico, psicológico, intelectual e social, complementando a ação da família e da comunidade". A educação deve, dessa forma, acompanhar esse processo, em outras palavras, a educação deve ser também um processo de abertura que surge e/ou que se modifica com o tempo.

\section{Metodologia}

Esta pesquisa tem caráter qualitativo, pois utilizou-se não só de métodos empíricos, como também houve uma abordagem teórica do conteúdo com os alunos em sala de aula, visando a aproximação da teoria à prática. Desta forma, configura-se como um estudo de 
caso.

O estudo de caso se caracteriza como um tipo de pesquisa cujo objeto é uma unidade que se analisa profundamente. [...] Tem por objetivo proporcionar vivência da realidade por meio da discussão, análise e tentativa de solução de um problema extraído da vida real. Enquanto técnica de ensino, procura estabelecer relação entre a teoria e a prática. (GODOY, 1995, p. 25).

Partindo dessa asserção, fez-se uma análise dos indivíduos e de suas realidades a fim de compreendê-las, uma vez que são elementos indissociáveis. As observações foram feitas através da interação entre dois públicos-alvo, a saber: 25 estudantes do $9^{\circ}$ ano $\mathrm{C}$ e 2 professores, ambos de uma escola municipal da cidade de Passira, Pernambuco. No decorrer do planejamento, buscou-se levantar indagações sobre quem é o povo brasileiro, bem como a importância das relações étnico-raciais na composição da nossa sociedade e no ensinoaprendizagem. Essa atuação propôs aos alunos o rompimento com a zona de conforto e sua participação ativa na formação do conhecimento.

Aprioristicamente, os estudos foram feitos a partir de uma aula lúdica com os alunos. Nesta aula foram apresentados vídeos sobre algumas matrizes que compõe nossa identidade, músicas alusivas de cada matriz e um poema de Castro Alves (O navio negreiro). Após essa exposição houve um debate que fomentou e incentivou a participação dos alunos acerca da busca pela representatividade, dando continuidade a este processo de sistematização e intercâmbio de conhecimentos formou-se três grupos com os alunos, cada aluno procuraria elementos herdados das matrizes e que permanecem, na configuração atual do Brasil. O objetivo principal, foi mostrar que as relações étnico-raciais devem acontecer de forma em que todas as matrizes possam ter fruição de seus direitos. A dinâmica propôs a diminuição da intolerância mostrando que herdamos costumes e/ou características físicas de outras culturas, por vezes inferiorizadas.

No segundo momento, realizou-se a aplicação de um questionário para um montante de nove alunos escolhido pelos professores, acerca das relações étnico-raciais e de como eles gostariam de aprender essa temática. Feito isso, aplicou-se outro questionário a dois professores, fazendo indagações sobre sua didática acerca da educação étnico-racial e como eles(as) trabalham, por exemplo, a interdisciplinaridade no tangente a este assunto abordado. O escopo do questionário foi, tão somente, checar se estava havendo a efetivação da troca de conhecimento acerca deste assunto e a partir dos resultados sugerir atividades que tratem das 
relações étnicos-raciais no processo de ensino e aprendizagem.

\section{Resultados e Discussões}

Em relação aos dados obtidos é possível inferir que tanto os alunos quanto alguns professores precisam compreender as dimensões epistemológica das relações étnico-raciais. Os professores reconhecem a importância da democratização do ensino para que a discussão ultrapasse o campo curricular/teórico e passem a incentivar o exercício da cidadania em seus alunos em uma educação básica pluralizada. É notório, portanto, que o professor tem conhecimento prévio da temática e, salienta, a importância de inovações no ensinoaprendizagem para as relações étnico-raciais.

Destarte, com essa esta prática é permissível analisar uma maior comunicação entre os docentes e os discentes, sendo permitido problematizar acerca desta temática indispensável às relações em sociedade. Dito isso, é evidente a necessidade de sair dos planos das ideias e pôr em prática as atividades dinamizadas, que acabam com a monotonia da sala. Para tanto, faz-se necessário a adoção de práxis pedagógicas que centralizam a importância desta temática como meio de compreensão social e de resgate ao orgulho cultural e do ideário de brasilidade.

Quadro 1: Respostas dos professores sobre as relações étnico-raciais nas vivências do ensino e da aprendizagem escolar.

\begin{tabular}{|c|c|}
\hline Questões & Respostas \\
\hline $\begin{array}{l}\text { 1) De que forma as relações étnico-raciais se } \\
\text { apresentam no processo de ensino e } \\
\text { aprendizagem? }\end{array}$ & $\begin{array}{l}\text { Professor 1: Discutir questões referente a } \\
\text { relação étnico-racial é um dos principais } \\
\text { desafios de educadores na atualidade. No } \\
\text { entanto, é indispensável a discussão da } \\
\text { história e cultura afro-brasileira e indígena na } \\
\text { sala de aula em prol de uma formação cidadã } \\
\text { responsável e para a construção de uma } \\
\text { sociedade justa, de igualdade de direitos e } \\
\text { democrática. } \\
\text { Professor 2: Em discussões e debates. }\end{array}$ \\
\hline $\begin{array}{l}\text { 2) Em que medida os conteúdos refletem e } \\
\text { discutem as relações étnico-raciais no }\end{array}$ & $\begin{array}{l}\text { Professor 1: Infelizmente, apesar de mais de } \\
\text { uma década da aprovação das leis } 10.639 / 03 \\
\text { e a } 11.645 / 08 \text {, nota-se que a discussão ainda } \\
\text { não ultrapassou os muros das universidades. } \\
\text { Isso é visível nos livros didáticos onde os } \\
\text { mesmos pouco contemplam as temáticas } \\
\text { (afro e indígenas). Sendo assim existe um } \\
\text { caminho longo e árduo a ser percorrido para a }\end{array}$ \\
\hline
\end{tabular}


ambiente escolar?

promoção da cidadania e do reforço à igualdade racial e social

Professor 2: Os conteúdos são discutidos quando tratamos sobre o negro na sociedade, a mulher... Quando também repensamos sobre algumas atitudes tomadas

Fonte: os autores, 2018

Aos alunos foi aplicado um questionário acerca do racismo, que é um dos resultados destes conflitos tangíveis as relações étnico-raciais. Indagou-se se eles sabiam o que era o racismo, depois convidou-os a se fazer uma autoavaliação perguntando se eles se consideravam racistas e por fim, perguntou se na escola, havia o racismo. Obteve os seguintes dados:

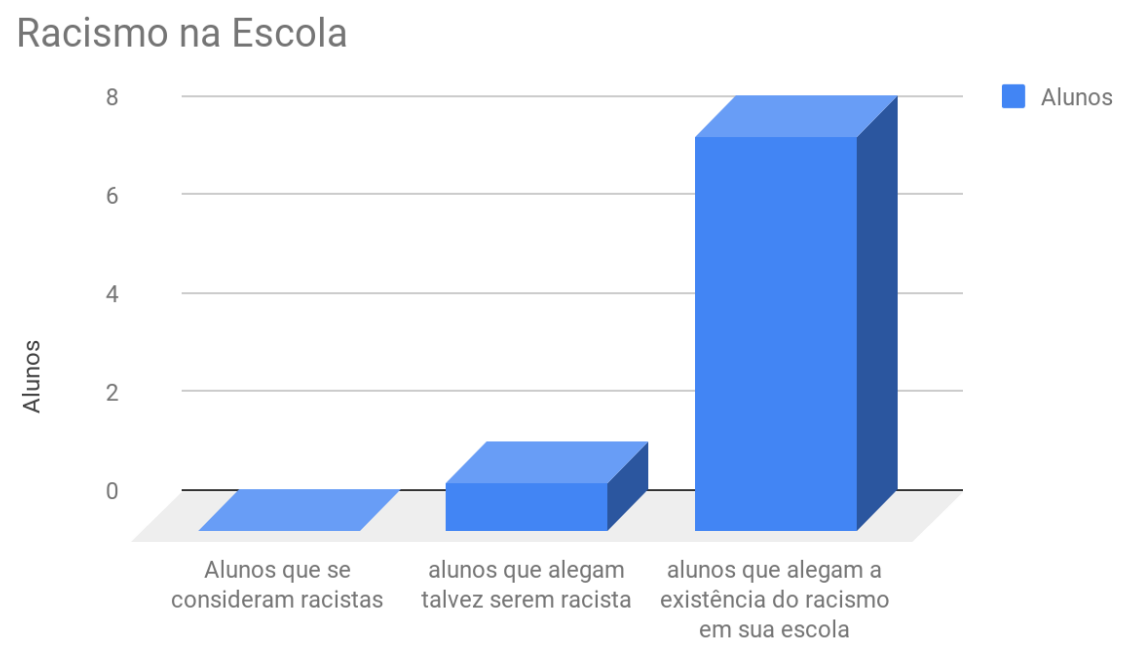

Fonte: Os autores, 2018.

A partir desse questionário foi perceptível que a maioria deles não se consideram racistas, mas que a mesma maioria afirma ter racismo na escola. Posto isso, é possível fazer uma comparação com os dados do IBGE (1988) que afirmou nessa entrevista que 97\% dos entrevistados não se consideram racistas, entretanto identificavam na mesma proporção alguém racista (amigo, parente, colega de trabalho...). O que dá a entender que no Brasil, o racista é sempre o outro. Foi possível, portanto, confirmar através deste questionário que essa problemática ainda perdura. 


\section{Conclusões}

Um dos clímaces levantados neste estudo foi a importância do debate nas escolas e a importância da democratização do ensino. As inovações tangentes as relações étnico-raciais poderiam ser feitas através de análises das obras de escritores negros, principalmente, para mostrar que eles foram participantes ativos do processo de transmissão cultural. Abordar os fatos históricos da colonização brasileira e seus desdobramentos problematizando seus reflexos na contemporaneidade.

expôs uma dificuldade nos docentes em passar esses conteúdos sócio históricos aos alunos, sendo assim, as aulas precisam de dinamização para que o assunto flua e haja a efetivação do entendimento. Poder-se-ia utilizar, então, de aulas de campo a centros históricos, bem como debates com representantes destes grupos, para fazer uma alusão do passado com o presente (o contexto social dos alunos).

\section{Referências}

BERTOLOTTO, R. Cidades em preto e branco. Disponível em: <https://tab.uol.com.br/racismo/>. Acesso em 12 de set. 2018.

BRASIL. Presidência da República. Casa Civil: subchefia para assuntos jurídicos. Lei n ${ }^{\circ}$ 9.394, de 20 de dezembro de 1996: estabelece as diretrizes e bases da educação nacional. Brasília, 1996. Disponível em: <http://www.planalto.gov.br/CCIVIL_03/ LEIS/L9394.htm〉. Acessado em: 09 set. 2018.

DAMATTA, R. O que faz o Brasil, Brasil?. Rio de Janeiro: Rocco, 1986.

GODOY, A. Introdução à pesquisa qualitativa e suas possibilidades. RAE-Revista de Administração de Empresas, São Paulo, v. 35, n. 2, p. 57-63, 1995.

GOMES, N. L. Relações étnico-raciais, educação e descolonização dos currículos. Currículo sem fronteiras, 2012. pp 98-109. Artigo. Departamento de Educação, UFMG, 2012.

LEIS, H. Sobre o conceito de interdisciplinaridade, caderno de pesquisa interdisciplinar em ciências humanas. Fpolis, agosto de 2005.

MUNANGA, K. Diversidade, identidade, etnicidade e cidadania. Conferência proferida no $1^{\circ}$ Seminário de III concurso Negro e Educação. São Paulo, 2003.

RIBEIRO, D. O povo brasileiro: a formação e o sentido do Brasil. $2^{\text {a }}$ ed. São Paulo: Companhia das Letras, 
SCHWARCZ, L. M. Espetáculo da miscigenação. São Paulo: Estud. av. vol.8 no.20, 1994.

PETRUCCIELI, J. Características étnico-raciais da população classificações e identidades. Rio de Janeiro: IBGE, 2013. 